\title{
Astaxanthin protects against diabetic cardiomyopathy via activation of Akt pathway in H9c2 cells
}

\author{
Yanyan $\mathrm{Hu}^{1 \star}$, Lin Shen ${ }^{1}$, Li Li ${ }^{2}$, Man $\mathrm{Li}^{1}$, Wenbin Yin ${ }^{1}$, Wei Liu ${ }^{1}$, Jian Zhang ${ }^{1}$ \\ ${ }^{1}$ Geriatrics Department of Shandong University Qilu Hospital, No. 107 Wen Hua West Road, ${ }^{2}$ Shandong University Qilu Medical \\ College, No. 44 Wen Hua West Road, Jinan City, Shandong Province, China
}

*For correspondence: Email: yanyanhu018@sina.com; Tel: +86-15917410131

\begin{abstract}
Purpose: To investigate the cardioprotective action of astaxanthin, and to elucidate its underlying mechanism of action in H9c2 cells.

Methods: Cell viability was determined by MTT assay. Intracellular reactive oxygen species (ROS) were evaluated using 2, 7-dichlorodihydro-fluorescein diacetate (H2DCFDA) staining. Cell apoptosis were assessed by determining caspase activities using colorimetric assay. The apoptotic cells were labelled with annexin V/PI staining and quantified by flow cytometry. Involvement of Akt signaling pathway was verified using western blot.

Results: The results revealed that astaxanthin $(5$ and $10 \mu \mathrm{M})$ dose-dependently reversed high glucoseinduced cell viability loss in H9c2 cells $(p<0.01$ and $p<0.001$, respectively). Astaxanthin inhibited intracellular ROS production, decreased caspase 3 and caspase 9 activities in high glucose-challenged H9c2 cells in a concentration-related manner $(p<0.05)$. Besides, astaxanthin markedly inhibited the number of apoptotic H9c2 cells induced by high glucose. Furthermore, western blot analysis demonstrated that astaxanthin upregulated the activation of Akt signaling.

Conclusion: Astaxanthin may protect high glucose induced diabetic cardiomyopathy via activation of Akt pathway, and thus deserves further investigation as a cardioprotective agent.
\end{abstract}

Keywords: Astaxanthin, Diabetic cardiomyopathy, Cardiomyocyte, Apoptosis, Akt pathway

\begin{abstract}
This is an Open Access article that uses a funding model which does not charge readers or their institutions for access and distributed under the terms of the Creative Commons Attribution License (http://creativecommons.org/licenses/by/4.0) and the Budapest Open Access Initiative (http://www.budapestopenaccessinitiative.org/read), which permit unrestricted use, distribution, and reproduction in any medium, provided the original work is properly credited.

Tropical Journal of Pharmaceutical Research is indexed by Science Citation Index (SciSearch), Scopus, International Pharmaceutical Abstract, Chemical Abstracts, Embase, Index Copernicus, EBSCO, African Index Medicus, JournalSeek, Journal Citation Reports/Science Edition, Directory of Open Access Journals (DOAJ), African Journal Online, Bioline International, Open-J-Gate and Pharmacy Abstracts
\end{abstract}

\section{INTRODUCTION}

Diabetic cardiomyopathy (DCM), characterized by myocardial disorder as well as systolic and diastolic dysfunction, has become a major public health issue. The presence of DCM is independent of recognized causes such as ischemic heart disorders or hypertension, but it can eventually result in heart failure and death [1]. Oxidative stress, chronic inflammation and high glucose intake are main risk factors for DCM [1]. Hyperglycemia is indeed a major mediator of cardiomyopathy through induction of a series of secondary transducers such as reactive oxygen species (ROS) [1]. Unwarranted ROS cause damage to genes and proteins that ultimately lead to cell apoptosis [2-4]. Oxidative stress is demonstrated to contribute to the initiation and progression of DCM [5]. Targeting ROS signaling 
may represent a possible strategy for preventing and treating DCM [2-4].

Astaxanthin is a carotenoid which exist in a wide variety of living organisms like krill, salmon, algae and flamingo [2]. Astaxanthin exhibits diverse pharmacological activities such as antioxidant, anti-inflammation, anti-hypertension and antihyperglycemia, etc [2-4]. Up to date, astaxanthin has been demonstrated to show a potential role in treating retinal damage and cognitive decline $[5,6]$. More importantly, astaxanthin could reduce glucose tolerance, increase serum insulin level and decrease blood glucose level in T2DM mouse model [7]. However, the cardioprotective role of astaxanthin has not been well addressed. Therefore, the primary purpose of this study was to verify the action of astaxanthin in high glucose-treated $\mathrm{H} 9 \mathrm{c} 2$ cardiomyoblasts, and to elucidate the underlying mechanism using numerous assays.<smiles>CC1=C(/C=C/C(C)=C/C=C/C(C)=C/C=C/C=C(C)/C=C/C=C(C)/C=C/C2=C(C)C(=O)[C@H](O)CC2(C)C)C(C)(C)CC(O)C1=O</smiles>

Figure 1: Chemical structure of astaxanthin

\section{EXPERIMENTAL}

\section{Cell culture}

Rat H9c2 cardiomyoblasts (ATCC, Manassas, USA) were maintained in Dulbecco's modified Eagle's medium (DMEM supplement with 2 $\mathrm{mM} / \mathrm{L}$ glutamine and $5.5 \mathrm{mM}$ glucose, Gibco, USA) containing $10 \%(\mathrm{v} / \mathrm{v})$ fetal bovine serum (FBS) and $1 \% \quad(\mathrm{v} / \mathrm{v})$ antibiotics (penicillinstreptomycin). The cells were cultured in $5 \%$ $\mathrm{CO}_{2}$ at $37{ }^{\circ} \mathrm{C}$. Astaxanthin was obtained from Sigma-Aldrich (Missouri, USA) and dissolved in dimethyl sulfoxide (DMSO). In all treatments, DMSO concentrations were no more than $0.1 \%$.

\section{Cell viability studies}

Briefly, H9c2 cells were cultured overnight in a 96-well plate (6000 cells/well) at $5 \% \mathrm{CO}_{2}, 37{ }^{\circ} \mathrm{C}$. The cells were pretreated with astaxanthin (0 $10 \mu \mathrm{M})$ for $2 \mathrm{~h}$ before culturing with high $\mathrm{D}$ glucose (HG, $33 \mathrm{mM}$ ) for $48 \mathrm{~h}$. MTT solution (5 $\mathrm{mg} / \mathrm{mL}$ in fresh medium) was then added into the wells. After another $3 \mathrm{~h}$ incubation, the cultured supernatant was replaced with $100 \mu \mathrm{L}$ DMSO. Optical density was detected at $540 \mathrm{~nm}$ using BioTek microplate reader (USA).

\section{Determination of intracellular ROS production}

Intracellular ROS were detected with the fluorescent ROS probe, 2', 7'-dichlorodihydrofluorescein diacetate $\left(\mathrm{H}_{2} \mathrm{DCFDA}\right)$ under the manufacturer's instruction (Invitrogen, USA). In brief, after appropriate treatments, H9c2 cells were incubated with $\mathrm{H}_{2}$ DCFDA solution $(10 \mu \mathrm{M})$ for $30 \mathrm{~min}$ at $37{ }^{\circ} \mathrm{C}$ in the dark. The cells were rinsed with PBS to remove extra fluorescent dye. Fluorescence intensities at $495 \mathrm{~nm}$ (excitation) and $529 \mathrm{~nm}$ (emission) were recorded with Fluoroskan Ascent FL fluorometer (Thermo, USA). The fold changes in ROS level were calculated by comparing to that of the control group.

\section{Evaluation of caspase activities}

Caspase-3 and -9 Colorimetric Assay Kits (Abcam, UK) were used to determine caspase activities following the manufacturer's instructions. After appropriate treatment, $\mathrm{H} 9 \mathrm{c} 2$ cells were collected and lysed with lysis buffer for $10 \mathrm{~min}$ on ice. Proteins $(50 \mu \mathrm{g})$ of each sample was added into a 96-well plate. Then $50 \mu \mathrm{L}$ reaction buffer (supplement with $10 \mathrm{mM}$ dithiothreitol) and $5 \mu \mathrm{L}$ caspase specific substrates were added to each well. The reaction was performed for $1.5 \mathrm{~h}$ at $37{ }^{\circ} \mathrm{C}$ in the dark. Absorbance at $405 \mathrm{~nm}$ was detected using BioTek microplate reader.

\section{Cell apoptosis detection}

Apoptotic cells was stained with Annexin V labeling kit (Roche, Swiss) following the manufacturer's instructions. After appropriate treatments, the cells were collected by centrifugation and re-suspended in $100 \mu \mathrm{L}$ Annexin $\mathrm{V}$ labeling solution for $15 \mathrm{~min}$ at room temperature in the dark. Data from 20,000 cells were collected and analyzed using flow cytometer (BD FACS Canto, USA).

\section{Western blot}

H92c cells were collected with radioimmunoprecipitation (RIPA) buffer. After lysis on ice for $30 \mathrm{~min}$, the proteins were obtained by centrifugation. Proteins $(20 \mu \mathrm{g})$ of each treatment group were loaded onto a $10 \%$ resolving SDS-PAGE gel. The electrophoretically developed proteins were transferred onto a PVDF membrane. Primary antibodies against phospho-Akt and Akt (Cell Signaling Technology, USA) were added to membrane and maintained overnight at $4{ }^{\circ} \mathrm{C}$. After removing extra primary antibodies with washing buffer, the membrane was then incubated with appropriate secondary 
antibodies for $2 \mathrm{~h}$ at room temperature. After removing the unbound secondary antibodies with washing buffer, the protein bands were detected and visualized using chemiluminescence ECL staining. Protein levels were normalized to $\beta$ actin, the internal control.

\section{Statistical analysis}

All results are presented as mean \pm the standard deviation (SD). One-way ANOVA followed by Bonferroni test was employed to analyze statistical differences between each group using Graphpad Prism 5 software. In all comparisons, $p<0.05$ was considered statistically significant.

\section{RESULTS}

\section{Astaxanthin prevented HG-induced cardiomyocyte cell death}

As shown in Figure $2 \mathrm{~A}$, astaxanthin alone at 10 $\mu \mathrm{M}$ did not affect $\mathrm{H} 9 \mathrm{c} 2$ cell viability. High glucose (33 mM) markedly reduced viable $\mathrm{H} 9 \mathrm{c} 2$ cell counts compared with the blank control group (Figure 2B). In the meantime, astaxanthin at 5 and $10 \mu \mathrm{M}$ significantly increased cell viability to $78.9 \pm 8.0 \%$ and $83.1 \pm 9.0 \%$, respectively, compared to $\mathrm{HG}$ alone group (64.5 $\pm 5.2 \%)$. These results indicated that astaxanthin showed great potential in protecting cardiomyocytes against high glucose-caused cell death.
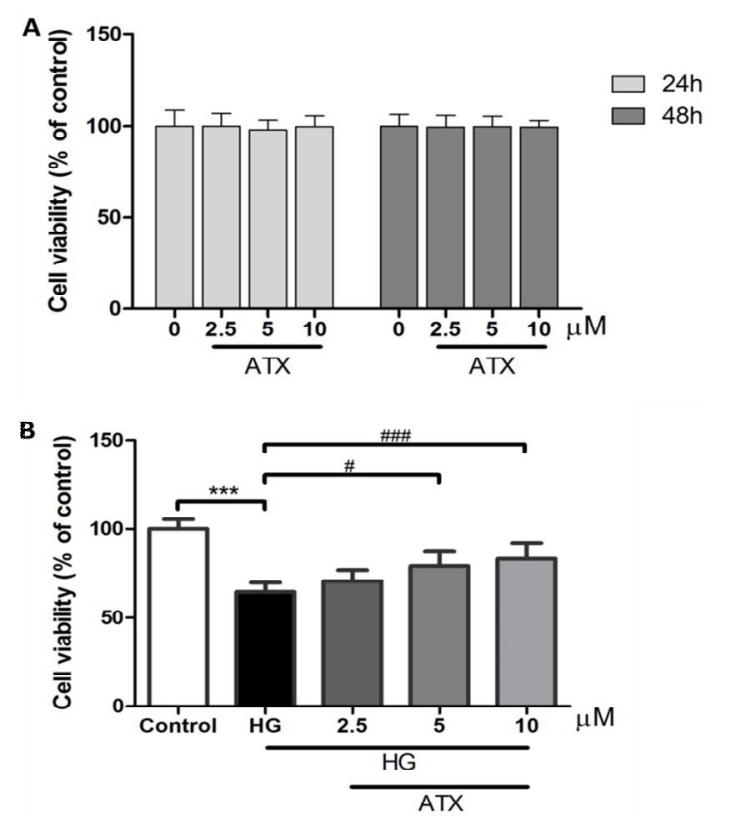

Figure 2: Preventive effects of astaxanthin against HG-casued cardiomyocytes cell death. Astaxanthin alone did not show cytotoxicity on H9c2 cells (A). Astaxanthin at 5 and $10 \mu \mathrm{M}$ significantly prevented high glucose induced $\mathrm{H} 9 \mathrm{c} 2$ cell death (B). Results are represented as mean $\pm S D(n=3) ;{ }^{* * *} p<0.001$ vs. control; $\# p<0.05, \# \# \# p<0.001$ vs. HG group

\section{Astaxanthin decreased HG-initiated intracellular ROS production}

As indicated in Figure 3, $33 \mathrm{mM}$ glucose significantly induced ROS generation in $\mathrm{H} 9 \mathrm{c} 2$ cells by about 3.7 folds as compared with control group. Astaxanthin dose-dependently decreased ROS level, especially after treatment at 5 and 10 $\mu \mathrm{M}$.

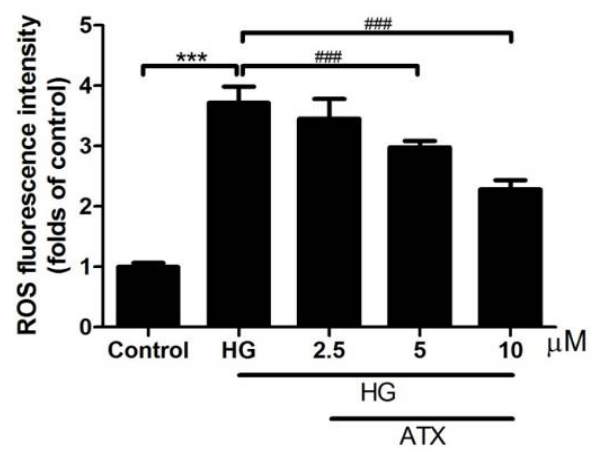

Figure 3: Effect of astaxanthin on HG-induced ROS production. Intracellular ROS levels were measured using ROS specific fluorescent probe $\mathrm{H}_{2}$ DCFDA. The fold changes in ROS level were calculated by comparing to that of the control group. Results were indicated as mean $\pm \mathrm{SD}(\mathrm{n}=3) ;{ }^{* * *} p<0.001$ vs. control; \#\#\#p<0.001 vs. HG group

\section{Astaxanthin reduced caspase activities in H9c2 cells}

Caspase enzymes are important proteins regulating cell apoptotic progression, so caspase- 3 and -9 activities were measured to evaluate the effects of astaxanthin on HG induced cardiomyocytes apoptosis. Compared to control group, caspase-3 and -9 activities increased 2.1- and 2.5-fold, respectively, upon high glucose stimulation (Figure 4). Pretreatment with astaxanthin at 5 and $10 \mu \mathrm{M}$ significant inhibited high glucose induced caspase- 3 and -9 activities.
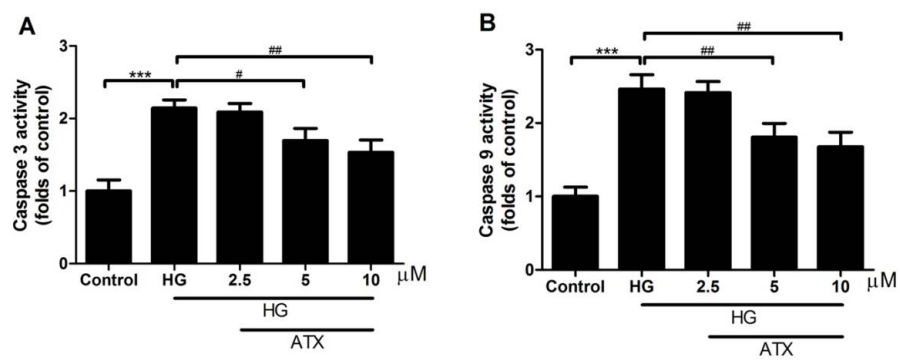

Figure 4: Effect of astaxanthin on caspase activities. Caspase-3 (A) and -9 (B) activities were determined using colorimetric kits. Fold-changes in absorbance density were represented as caspase activity compared to that of control group. Results are indicated as mean $\pm \mathrm{SD}(\mathrm{n}=3) ;{ }^{* * *} p<0.001$ vs. control; $\# p<0.05$ and $\# \# p<0.01$ vs. HG group 


\section{Astaxanthin inhibited HG-induced cell apoptosis}

As shown in Figure 5, exposure to high glucose significantly increased early apoptotic cells (12.2 $\pm 2.0 \%$ vs. $3.6 \pm 0.6 \%)$. Astaxanthin pretreatment at $10 \mu \mathrm{M}$ markedly decreased the portion of apoptotic cells to $7.5 \pm 1.8 \%$. These results implied that astaxanthin showed protective effects against HG mediated cardiomyoblasts cell apoptosis.

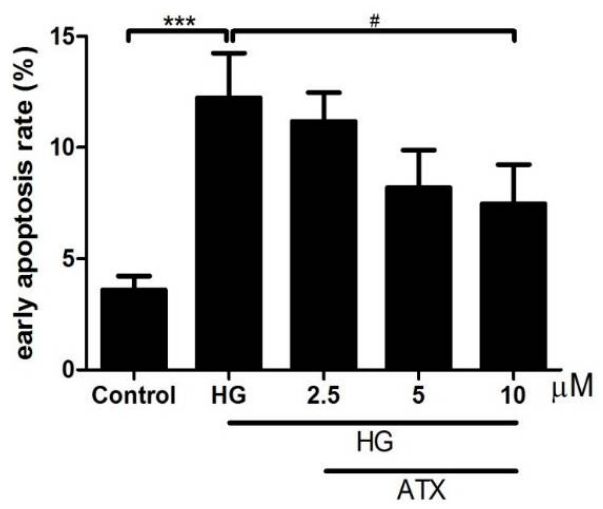

Figure 5: Effect of astaxanthin on HG-mediated cardiomyocytes apoptosis. Cells with Annexin $\mathrm{V}^{+} \mathrm{PI}^{-}$ represents the early apoptotic cells in flow cytometric analysis. Results are indicated as mean $\pm S D(n=3)$; ${ }^{* * *} p<0.001$ vs. control; $\# p<0.05$ vs. HG group

\section{Astaxanthin-activated Akt signaling}

To investigate intracellular signaling pathway involved in the protective actions of astaxanthin on HG-mediated cell apoptosis, both phosphorylated and total Akt proteins were detected and analyzed by western blot. There were no obvious changes regarding total Akt proteins between each group (Figure 6). The phosphorylation of Akt was significantly inhibited by HG treatment, which was significantly reversed by astaxanthin pretreatment in concentration-related way. These results demonstrated that astaxanthin protects against HG-induced cardiomyocytes apoptosis through activation of Akt signaling.

\section{DISCUSSION}

In the present study, astaxanthin was demonstrate to protect cardiomyocytes against high glucose-induced damage via inhibition of ROS generation and cell apoptosis. The beneficial effects of astaxanthin were mediated via activating Akt signaling. Diabetes mellitus contributes to the pathogenesis of various cardiovascular disorders known as the most common causes of mortality worldwide [8].
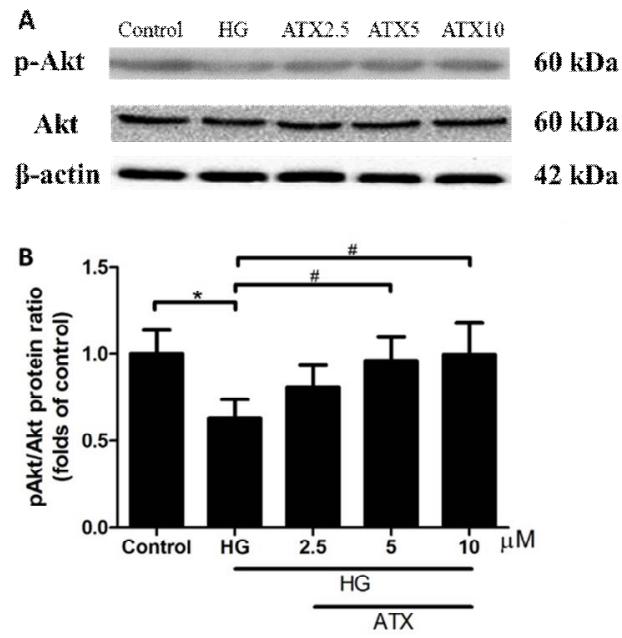

Figure 6: Astaxanthin activated Akt signaling in HGtreated cardiomyocytes. Primary antibodies against phospho-Akt and Akt were used in this study. The protein levels was quantified by densitometry using ImageJ software. Results were indicated as mean \pm $\mathrm{SD}(\mathrm{n}=4) ;{ }^{*} p<0.05$ vs. control; $\# p<0.05$ vs. HG group

It is reported that DCM affects approximately 12 $\%$ diabetic patients and increases the risk of death [9]. Getting a better understanding of the progression of DCM will undoubtedly contribute to the development of more effective treatments.

Hyperglycemia and lipotoxicity are the major metabolic disturbances contributing to the pathogenesis of DCM. Excessive ROS generation in hyperglycemic tissues causes adverse functional and structural changes in heart [10]. Oxidative stress induces excess production of mitochondrial superoxide radical followed by several other reactive species which are not counter-balanced by the innate antioxidant defense system [11]. The superoxide radicals interact with other intracellular components including nitric oxide, leading to form nitrotyrosine species, which are upregulated in myocardial biopsies of T2DM patients [12,13].

These reactive molecules lead to cardiomyocyte cell apoptosis, as well as some abnormal gene expression related to signal transduction $[14,15]$. Targeting oxidative stress related signaling pathways is a feasible strategy to prevent and treat DCM $[13,16]$. Multiple anti-oxidative drugs such as thioredoxin 2 and myricitrin showed great potential in preventing DCM through inhibition of oxidative stress [17]. In the present study, ROS was overproduced in high glucose stimulated cardiomyocyte, whilst astaxanthin was found to reduce the level of ROS (Figure 3), indicating astaxanthin deserves to be further studied as a drug for treating DCM. 
Apoptosis of cardiomyocyte contributes to cardiac remodeling and heart failure during the progress of DCM [17]. Emerging evidences demonstrate that high glucose activates NADPH oxidase which causes ROS production. Reactive oxygen species triggers cell apoptosis through intrinsic mitochondrial pathway. Activation of the initiator caspase 9 and following e $\square$ ector caspases 3 is functioned as executors to downstream molecular activities, leading to cell apoptosis. In this study, caspase- 3 and -9 activities were markedly upregulated upon high glucose treatment, which were consistent with the previous reports [10]. Moreover, astaxanthin was demonstrated to suppress the activities of these two apoptosis-related enzymes. In addition, astaxanthin treatment significantly reduced the percentages of early apoptotic cells in high glucose treated H9c2 cells, suggesting astaxanthin is an effective anti-apoptosis drug.

Dysregulation of intracellular molecules participates in the pathogenesis of DCM, including Akt and extracellular signal-regulated kinase 1 (ERK1) [10]. Defective phosphatidylinositol 3-kinase (PI3K)-Akt pathway has been observed in diabetes. It is necessary to upregulate the critical level of Akt phosphorylation to protect diabetic myocardium [18]. Phosphorylation of Akt modulates cell survival in part via inhibition of pro-apoptotic signals like Bad, Bax. Activation of Akt signaling can suppress apoptosis signal-regulating kinase 1 (ASK1) activity, finally inhibit apoptosis [19]. Furthermore, elevated pAkt was observed in diabetic hearts of transgenic mice which constitutively expressed active $\mathrm{PI} 3 \mathrm{~K}$, indicating $\mathrm{PI3K} /$ Akt is likely to participate in protection of diabetic cardiac injury [9].

Various molecules such as Annexin A1 and carbamylated erythropoietin have been shown to attenuate cardiomyopathy through activation of Akt signaling in diabetes $[20,21]$. In the current study, western blotting data which were used to assess the expression and phosphorylation of Akt protein suggest that activation of Akt signaling was inhibited in high glucose-mediated cardiomyocyte apoptosis and was recovered by astaxanthin treatment.

Astaxanthin is a natural carotenoid found in many types of marine organisms and some fungi such as Phaffia rhodozyma [18]. Astaxanthin exhibits numerous biological activities including antioxidant, anti-inflammation, anti-hypertension, anti-hyperglycemia as well as neuroprotective effect $[22,23]$. The efficacy of astaxanthin as an antioxidant drug was comparable to classic vitamin $C$ and other carotenoids like $\beta$-carotene in vitro. In the present study, astaxanthin was firstly demonstrated to protect cardiomyocytes through inhibition of ROS induced apoptosis. More in vivo studies and clinical trials are warranted to further demonstrate the application of astaxanthin in treating diabetic cardiomyopathy.

\section{CONCLUSION}

The findings of the current study indicate that astaxanthin protects cardiomyocytes against high glucose-induced apoptosis by reducing ROS generation, and activating Akt pathway. However, in vivo studies should be undertaken to further develop astaxanthin as a potential medicine for preventing diabetic cardiomyopathy.

\section{DECLARATIONS}

\section{Acknowledgement}

This study was supported by Shandong Provincial Natural Science Foundation, China (no. ZR2015HM052).

\section{Conflict of interest}

No conflict of interest is associated with this work.

\section{Contribution of authors}

We declare that this work was done by the authors named in this article and all liabilities pertaining to claims relating to the content of this article will be borne by the authors. This study was designed by Yanyan $\mathrm{Hu}$. The experiments in this study were done by Wenbin Yin, Jian Zhang, Wei Liu and Man Li. Lin Shen and Wei Liu performed the data analysis. Li Li reviewed this manuscript and gave comments for conducting this study. Yanyan Hu drafted this manuscript and supervised by the other authors.

\section{REFERENCES}

1. Al-Lawati JA. Diabetes Mellitus: A Local and Global Public Health Emergency! Oman Med J 2017; 32(3): 177-179.

2. Voulgari C, Papadogiannis D, Tentolouris N. Diabetic cardiomyopathy: from the pathophysiology of the cardiac myocytes to current diagnosis and management strategies. Vasc Health Risk Manag 2010; 6: 883-903.

3. Zhou YT, Grayburn P, Karim A, Shimabukuro M, Higa M, Baetens $D$, Orci L, Unger RH. Lipotoxic heart disease in obese rats: implications for human obesity. Proc Natl Acad Sci U S A 2000; 97(4): 1784-1789. 
4. Monkemann $H$, De Vriese AS, Blom HJ, Kluijtmans LA, Heil SG, Schild HH, Golubnitschaja O. Early molecular events in the development of the diabetic cardiomyopathy. Amino Acids 2002; 23(1-3): 331-336.

5. Fonarow GC, Srikanthan P. Diabetic cardiomyopathy. Endocrinol Metab Clin North Am 2006; 35(3): 575-599, ix.

6. Hayat SA, Patel B, Khattar RS, Malik RA. Diabetic cardiomyopathy: mechanisms, diagnosis and treatment. Clin Sci (Lond) 2004; 107(6): 539-557.

7. Retnakaran $R$, Zinman B. Type 1 diabetes, hyperglycaemia, and the heart. Lancet 2008; 371(9626): 1790-1799.

8. Falcao-Pires $I$, Leite-Moreira AF. Diabetic cardiomyopathy: understanding the molecular and cellular basis to progress in diagnosis and treatment. Heart Fail Rev 2012; 17(3): 325-344.

9. Huynh K, Bernardo BC, McMullen JR, Ritchie RH. Diabetic cardiomyopathy: mechanisms and new treatment strategies targeting antioxidant signaling pathways. Pharmacol Ther 2014; 142(3): 375-415.

10. Wilson AJ, Gill EK, Abudalo RA, Edgar KS, Watson CJ, Grieve DJ. Reactive oxygen species signalling in the diabetic heart: emerging prospect for therapeutic targeting. Heart 2017.

11. Visioli $F$, Artaria C. Astaxanthin in cardiovascular health and disease: mechanisms of action, therapeutic merits, and knowledge gaps. Food Funct 2017; 8(1): 39-63.

12. Sueishi $Y$, Ishikawa M, Yoshioka D, Endoh N, Oowada S, Shimmei $M$, Fujii $H$, Kotake $Y$. Oxygen radical absorbance capacity (ORAC) of cyclodextrin-solubilized flavonoids, resveratrol and astaxanthin as measured with the ORAC-EPR method. J Clin Biochem Nutr 2012; 50(2): 127-132.

13. Uchiyama K, Naito Y, Hasegawa G, Nakamura N, Takahashi J, Yoshikawa T. Astaxanthin protects betacells against glucose toxicity in diabetic $d b / d b$ mice. Redox Rep 2002; 7(5): 290-293.

14. Yeh PT, Huang HW, Yang CM, Yang WS, Yang $\mathrm{CH}$. Astaxanthin Inhibits Expression of Retinal Oxidative
Stress and Inflammatory Mediators in StreptozotocinInduced Diabetic Rats. PLoS One 2016; 11(1): e0146438.

15. Okazaki Y, Okada S, Toyokuni S. Astaxanthin ameliorates ferric nitrilotriacetate-induced renal oxidative injury in rats. J Clin Biochem Nutr 2017; 61(1): 18-24.

16. Hussein G, Nakagawa T, Goto H, Shimada $Y$, Matsumoto $K$, Sankawa U, Watanabe H. Astaxanthin ameliorates features of metabolic syndrome in SHR/NDmcr-cp. Life Sci 2007; 80(6): 522-529.

17. Lorenzo-Almoros A, Tunon J, Orejas M, Cortes M, Egido $J$, Lorenzo O. Diagnostic approaches for diabetic cardiomyopathy. Cardiovasc Diabetol 2017; 16(1): 28.

18. Frustaci A, Kajstura J, Chimenti C, Jakoniuk I, Leri A, Maseri A, Nadal-Ginard B, Anversa P. Myocardial cell death in human diabetes. Circ Res 2000; 87(12): 11231132.

19. Shen E, Li Y, Shan L, Zhu H, Feng Q, Arnold JM, Peng T. Rac1 is required for cardiomyocyte apoptosis during hyperglycemia. Diabetes 2009; 58(10): 2386-2395.

20. Li H, Xu C, Li Q, Gao X, Sugano E, Tomita $H$, Yang L, Shi $S$. Thioredoxin 2 Offers Protection against Mitochondrial Oxidative Stress in H9c2 Cells and against Myocardial Hypertrophy Induced by Hyperglycemia. Int J Mol Sci 2017; 18(9).

21. Zhang $B$, Shen $Q$, Chen $Y$, Pan R, Kuang S, Liu G, Sun G, Sun X. Myricitrin Alleviates Oxidative Stress-induced Inflammation and Apoptosis and Protects Mice against Diabetic Cardiomyopathy. Sci Rep 2017; 7: 44239.

22. Sun $X$, Chen RC, Yang $Z H$, Sun GB, Wang $M$, Ma $X J$, Yang $L J$, Sun $X B$. Taxifolin prevents diabetic cardiomyopathy in vivo and in vitro by inhibition of oxidative stress and cell apoptosis. Food Chem Toxicol 2014; 63: 221-232.

23. Ji L, Liu Y, Zhang Y, Chang W, Gong J, Wei S, Li X, Qin $L$. The antioxidant edaravone prevents cardiac dysfunction by suppressing oxidative stress in type 1 diabetic rats and in high-glucose-induced injured H9c2 cardiomyoblasts. Can J Physiol Pharmacol 2016; 94(9): 996-1006. 